\title{
Cytophotometric and flow cytometric DNA content of isolated glands in gastric neoplasia
}

\author{
Y Kitayama, S Nakamura, H Sugimura, I Kino
} Pathology,

Hamamatsu

University School of

Medicine, Japan

Y Kitayama

H Sugimura

I Kino

Department of

Pathology,

Hamamatsu

University Hospital,

Japan

S Nakamura

Correspondence to: Dr I Kino, First Departmen of Pathology, Hamamatsu Oniversity School of Medicine, 3600 Handa-cho, Accepted for publication 15 July 1994
First Department of Medicine, 3600 Handa-cho,
Hamamatsu 431-31, Japan.

\begin{abstract}
The gland isolation method was applied to various gastric lesions to measure DNA content by cytophotometry and flow cytometry for the first time. By incubating and agitating fresh specimens from surgically resected stomachs in calciummagnesium free Hanks's balanced salt solution (CMFH) containing EDTA, many neoplastic glandular epithelial cells were successfully isolated from the stroma, and their characteristic three dimensional features were seen morphologically. The DNA content of pure nuclear suspensions of isolated glands was obtained by cytophotometry and flow cytometry staining with $4^{\prime}$,6-diamino-2phenylindole dihydrochloride (DAPI) and propidium iodide, respectively. Compared with histological grading, the frequency of the DNA aneuploidy of cancer with moderate or poor differentiation by cytophotometry $(75 \%)$ was significantly higher than that of well differentiated cancer $(25 \%)$, but the histological typing of gastric cancer DNA frequency were not correlated. This method allowed us to detect small aneuploid peaks by flow cytometry, which were previously masked by contaminating interstitial cells. The frequency of DNA aneuploidy detected by flow cytometry $(87 \cdot 5 \%)$ was higher than detected by cytophotometry $(58 \cdot 3 \%)$. The results of these studies shows the feasibility of this technique for
\end{abstract}
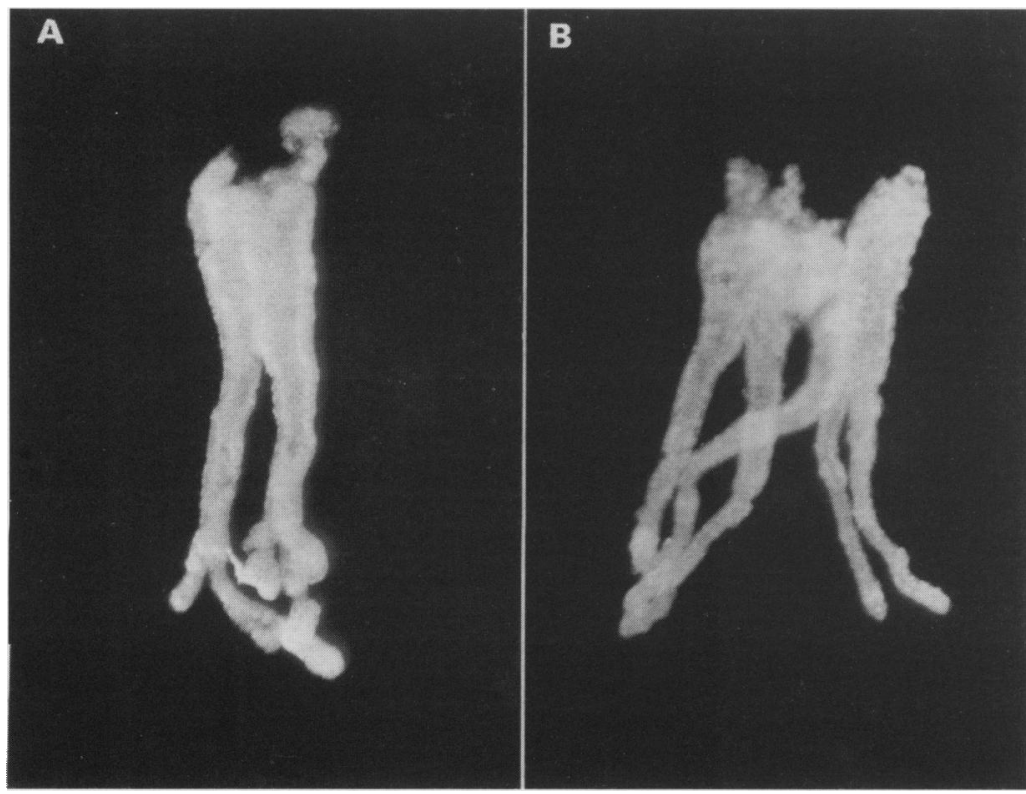

Figure 1: Single crypt epithelium of the pyloric (A) and fundic (B) mucosa as shown by stereomicroscope. The crypts are free from basement membrane of the fibrous stroma. analysing the DNA content of various lesions of the stomach.

(Gut 1995; 36: 516-521)

Keywords: gastric neoplasia, gland isolation method, cytophotometry, flow cytometry, DNA.

Many studies on the DNA content in gastric carcinomas have been performed by flow cytometry. ${ }^{1-6}$ Most have been carried out retrospectively, using single nuclei suspensions retrieved from formalin fixed, paraffin wax embedded tissues. ${ }^{1-4}$ With this method, however, DNA fragmentation and partial nuclei have caused large amounts of background debris and high coefficient of variation, interfering with accurate recognition of DNA ploidy of gastric neoplasms.

Conventional methods using interstitial cells as the internal diploid standard in either fixed or fresh materials could cause contamination of aneuploid tumour cell nuclei, because the ratio of tumour nuclei to interstitial nuclei is unknown and indeterminable. Moreover, a mixture of the two nuclei may prevent recognition of small aneuploid peaks or near diploid aneuploid peaks of tumour cell nuclei. ${ }^{12}$

Given these circumstances, we isolated single glands from gastric mucosal lesions without interstitial cells and were able to obtain accurate ploidies of these lesions. We report the gland isolation method, ${ }^{7-12}$ three dimensional structures of isolated glands, and their DNA ploidies obtained by cytophotometry ${ }^{11}$ and flow cytometry.

\section{Methods}

Samples

Seventy eight gastrectomy or biopsy specimens were obtained from 62 patients with carcinoma (48 cases), adenoma (eight cases), hyperplastic polyp (10 cases), and intestinal metaplasia (six cases). Forty two of 48 carcinoma patients (mean age: 66.3 years, 30 males and 18 females) were in the advanced stage of the disease.

All the specimens were placed in cold $\left(4^{\circ} \mathrm{C}\right)$ calcium and magnesium free Hanks's balanced salt solution (CMFH). Small control pieces of normal pyloric and fundic mucosa were removed from regions as distant from the lesions as possible.

Gland isolation procedure

A modification of the method of Cheng was used for isolation of the gastric epithelium. ${ }^{89}$ 
Each specimen was cut into squares of $2-3 \mathrm{~mm}$ and incubated for 30 minutes at $37^{\circ} \mathrm{C}$ in CMFH containing $30 \mathrm{mM}$ EDTA. The glands were removed by stirring in cold $\mathrm{CMFH}$, and were sedimented by gentle centrifugation. The supernatant was aspirated and the glands were fixed with $70 \%$ ethanol alcohol. The mucosa remaining after isolation was fixed with $70 \%$

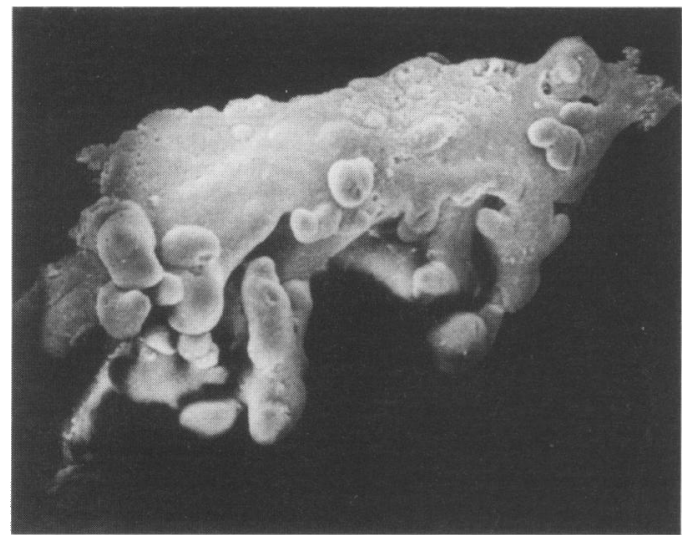

Figure 2: Histological features of papillotubular carcinoma shown by scanning electron microscope. The gland consists of small cystic and irregular branches.

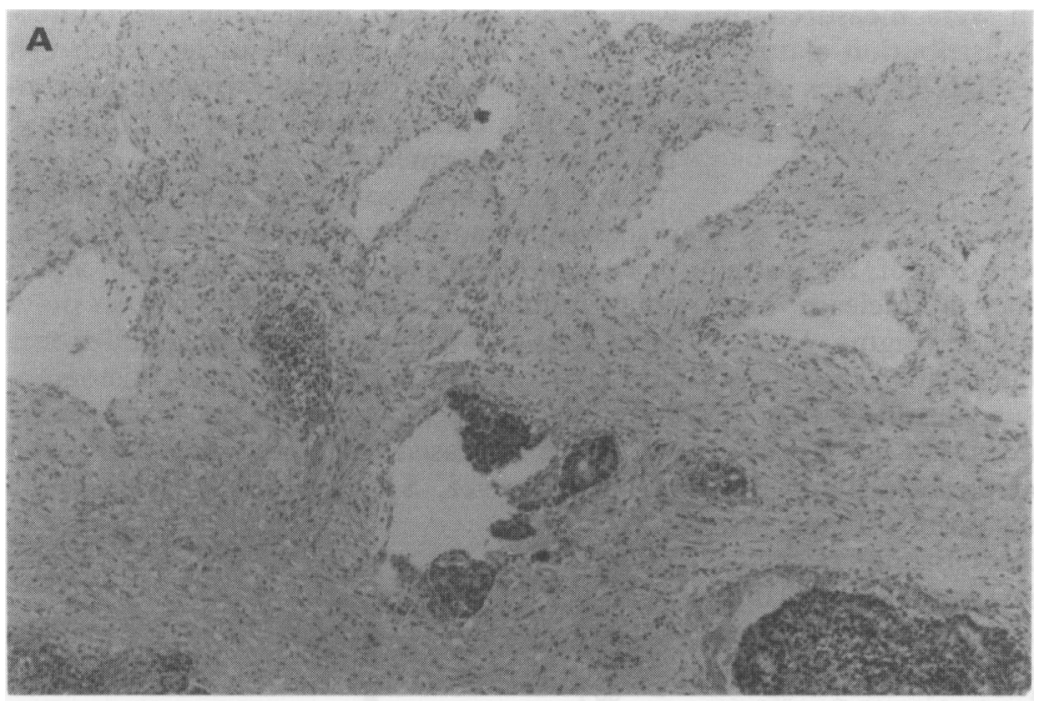

$\mathbf{B}$

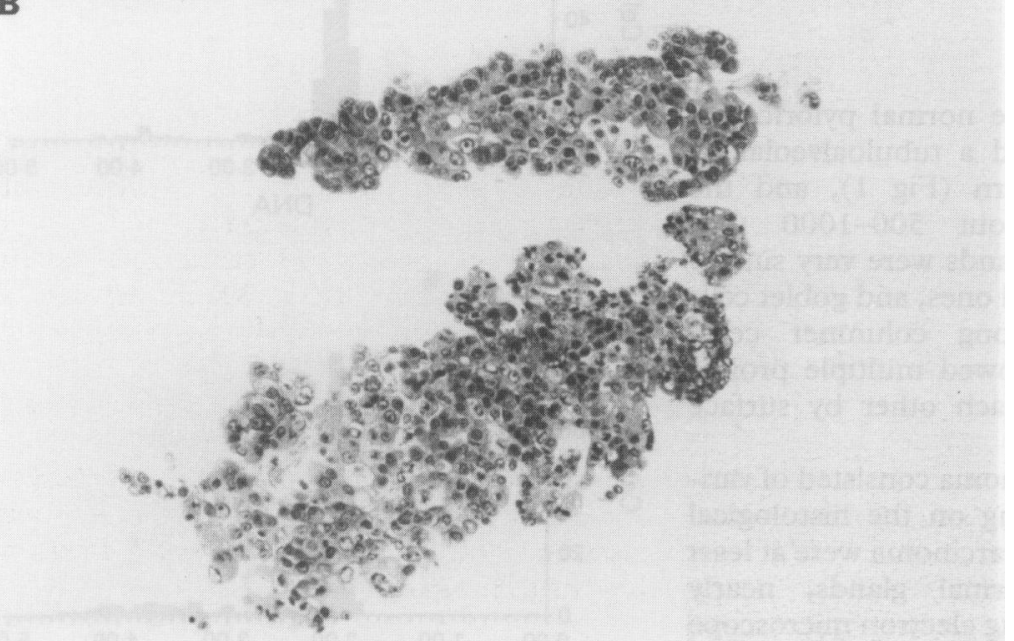

Figure 3: (A) Histological features of medullary carcinoma. Some cavities can be seen in the stroma remaining after cancer tissue isolation (haematoxylin and eosin stain original magnification $\times 40$ ); (B) photomicrograph showing continuous section of isolated cancer tissue (haematoxylin and eosin stain original magnification $\times 100$ ). ethanol, 1112 stained with haematoxylin and eosin, and subjected to pathological diagnosis. Histopathological classification was carried out based on the General Rules for Gastric Cancer Study in Japan. ${ }^{13}$ In terms of histological grading for differentiation, tubular type of carcinomas was divided into well (tub 1) and moderately (tub 2) differentiated according to the degree of glandular formation of the cancer epithelium. Diffuse carcinomas were divided into the solid type (por 1) and non-solid type (por 2).

\section{Morphological findings}

After fixation, epithelia consisting of normal pyloric and fundic glands, benign lesions, and mainly tubular carcinomas were observed under stereomicroscope. Some epithelia were fixed with osmium acid and observed by scanning electron microscope (ASID, 3D2 type Nihondenshi Japan). To detect intestinalised epithelium, isolated glands from the gastric mucosa were stained with alcian blue to identify goblet cells under stereomicroscope.

\section{Cytophotometric measurement of nuclear DNA} content

An aliquot of isolated epithelia was dissociated by treatment with $0.025-0.0125 \%$ pepsin (pH $1.5)$ for five minutes at $37^{\circ} \mathrm{C}$ in a water bath. The single nuclei suspensions in phosphate buffer were filtered through a nylon mesh (37 $\mu \mathrm{m})$ and smeared on non-fluorescent glass slides with an automatic smear maker (Cytospin 3, Shandon, England), and stained with 4',6-diamino-2-phenylindole dihydrochloride (DAPI) (Sigma, USA) at a concentration of $50 \mu \mathrm{g} / \mathrm{ml}$ in a buffer $(\mathrm{pH} 7 \cdot 4)$ for 60 minutes at room temperature. ${ }^{11}{ }^{14-17}$ The nuclear DNA content was measured with an epi-illumination cytophotometer (BH2RFL, Olympus, Japan). The nuclear fluorescence intensities of 200 normal epithelial cells were measured to obtain an internal standard of diploid DNA content (2C) and 200 neoplastic

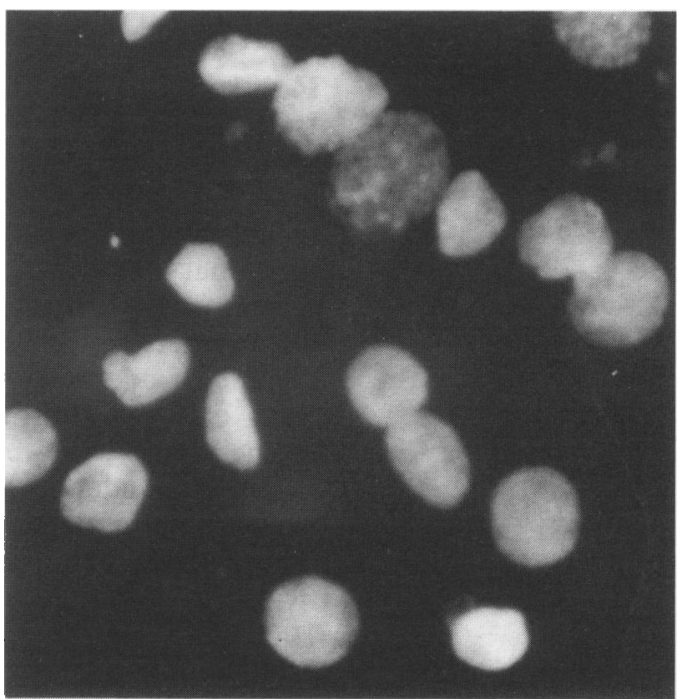

Figure 4: Cell nuclear fluorescence of carcinoma. Fluorescence intensity varied with the position in the cell cycle (original magnification $\times 400$ ). 

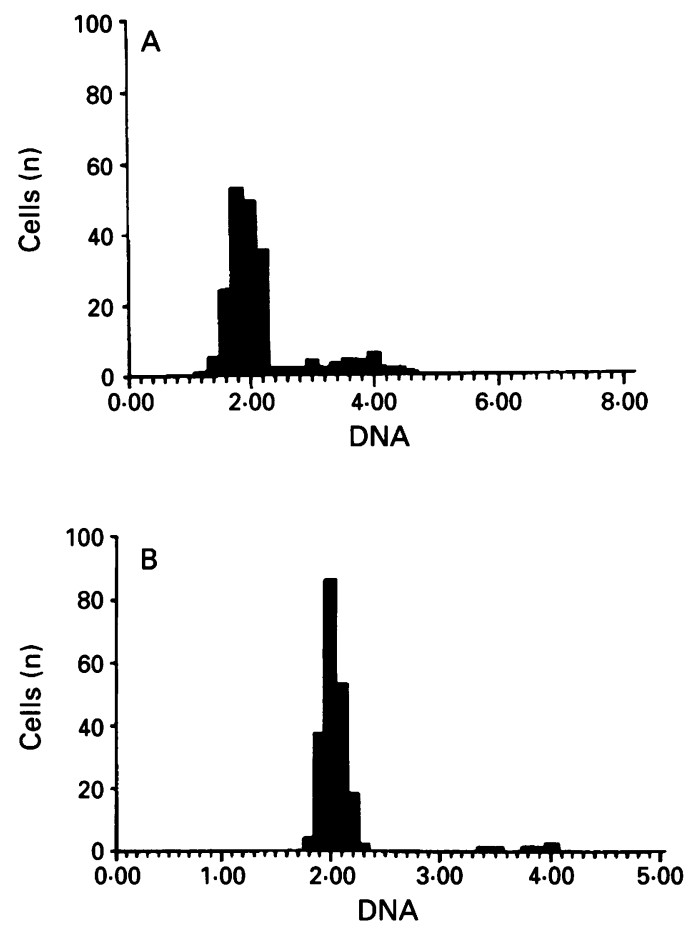

Figure 5: (A) Adenoma with some increased proliferative cells; (B) intestinal metaplasia with few $S$ phase cells.

cells from each specimen were measured. A histogram of the DNA distribution pattern was obtained, and the DNA index was calculated. ${ }^{11} 1718$

\section{Processing for flow cytometry}

The single nuclei suspensions of the same cases were treated with ribonuclease and stained with propidium iodide (Sigma, USA). In each case, samples were divided into three species of single nuclei suspensions - that is, normal cell nuclei, neoplastic cells, and mixtures of normal and neoplastic cell nuclei at a ratio of 1:1 (or at various ratios). These suspensions were on an Epics Profile (Coulter Corporation, Miami, USA) and about 20000 cell nuclei from each sample were counted. The DNA index and coefficient of variation were also calculated. ${ }^{19-21}$

\section{Results}

Isolated glands from the normal pyloric and fundic mucosa disclosed a tubuloalveolar or branched tubular pattern (Fig 1), and the mean length was about $500-1000 \mu \mathrm{m}$. Intestinal metaplastic glands were very similar to normal large intestinal ones, and goblet cells were interspersed among columner cells. Glands of adenoma showed multiple projections connected with each other by surface epithelium.

Glands of adenocarcinoma consisted of various structures depending on the histological type. Glands of tubular carcinoma were at least twice as long as normal glands, nearly 1000-2000 $\mu \mathrm{m}$. Scanning electron microscope examination of papillotubular carcinoma showed glands with irregular branching and length (Fig 2). Occasionally medullary carcinoma was isolated, and isolated cancer tissue
TABLE I DNA ploidy pattern of gastric mucosal lesions classified by cytophotometry and flow cytometry.

\begin{tabular}{|c|c|c|c|c|c|}
\hline \multirow[b]{3}{*}{ Diagnosis } & \multirow[b]{3}{*}{ Total } & \multicolumn{4}{|c|}{ Cases classified as aneuploid by } \\
\hline & & \multicolumn{2}{|c|}{ Cytophotometry } & \multicolumn{2}{|c|}{ Flow cytometry } \\
\hline & & No & $\%$ & No & $\%$ \\
\hline \multicolumn{6}{|l|}{ Cancer } \\
\hline tub 1 & 16 & 4 & $20 \cdot 0$ & 14 & $87 \cdot 5$ \\
\hline tub 2 & 22 & 18 & $81 \cdot 8$ & 20 & $90 \cdot 1$ \\
\hline por 1 & 4 & 2 & $50 \cdot 0$ & 2 & $50 \cdot 0$ \\
\hline por 2 & 6 & 4 & $66 \cdot 7$ & 6 & 100 \\
\hline Total & 48 & 28 & $58 \cdot 3$ & 42 & $87 \cdot 5$ \\
\hline Adenoma & 8 & 0 & 0 & 0 & 0 \\
\hline Hyperplastic polyp & 10 & 0 & 0 & 0 & 0 \\
\hline Intestinal metaplasia & 6 & 0 & 0 & 1 & $16 \cdot 7$ \\
\hline
\end{tabular}

Histological classification of the gastric carcinoma was according to the Japanese Research Society for Gastric Cance (1985). tub 1, well differentiated tubular carcinoma; tub 2, moderately differentiated tubular carcinoma; por 1 and por 2 , solid type and non-solid type of poorly differentiated adenocarcinoma.

and remaining mucosa were seen as well (Fig 3).

\section{DNA histogram by cytophotometry}

Fluorescent nuclei of normal, adenoma, and carcinoma cells stained with DAPI showed different features. Nuclei of adenoma were small and spindle shaped, while nuclei of carcinoma were larger and had more intensive fluorescence (Fig 4) than normal nuclei. Each cell maintained its nuclear shape, without destruction, so that exact measurement of single cell DNA was performed.

In the normal epithelial cells, the DNA distribution pattern consisted of a single high peak in $(\mathrm{G} 0 / \mathrm{G} 1)$ phase in the 2c range and a small number of cells up to $4 \mathrm{c}$ with no polyploid cells exceeding the $4 \mathrm{c}$ range. In adenoma and hyperplastic polyp, the DNA histogram resembled the normal pattern but proliferating cells were increased (Fig 5). In intestinal metaplasia, however, $\mathrm{S}$ phase cells tended to be
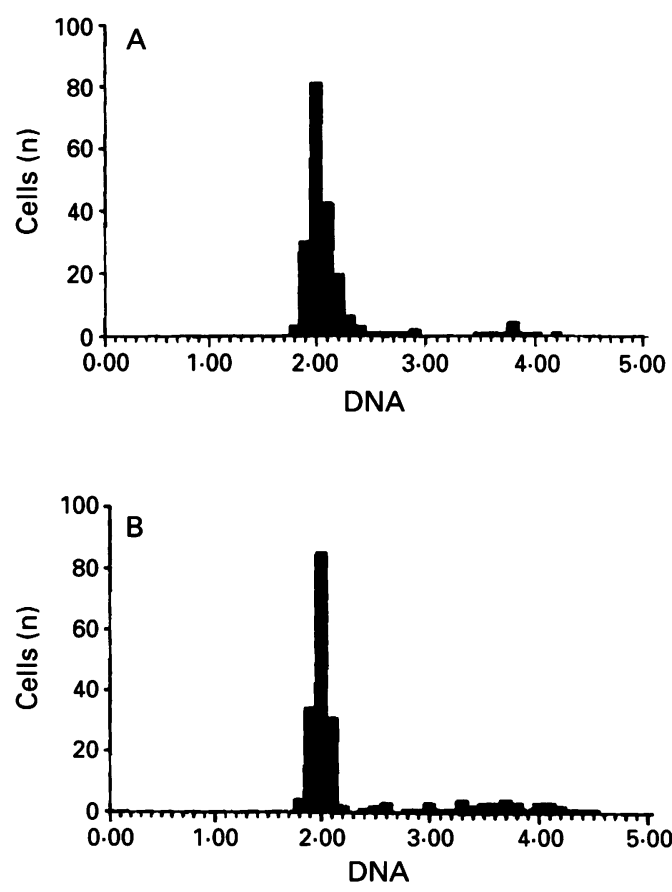

Figure 6: Representative DNA distribution pattern shown by cytophotometry. (A) Normal internal standard; (B) diploidy of the first pattern with a few higher polyploid cells. 

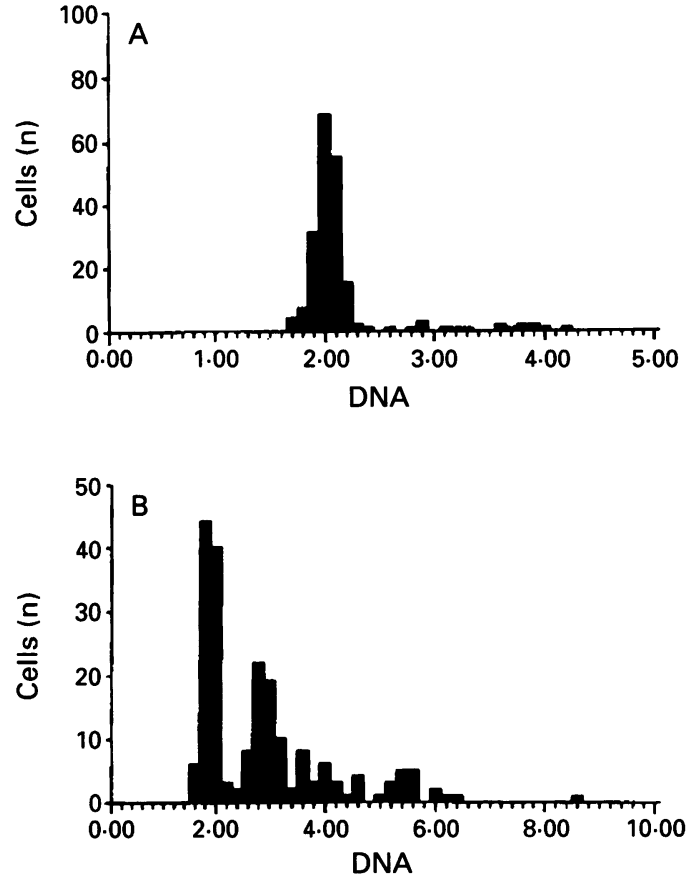

Figure 7: (A) Normal internal standard; (B) aneuploidy showing mosaicism with diploidy and tetraploidy.

diminished (Fig 5). Cancers whose predominant peak had a DNA index $<1 \cdot 10$ were considered diploid, while those with a DNA index $\geqslant 1 \cdot 10$ were considered aneuploid, and three patterns were recognised.

Diploidy (20 cases) - this pattern consisted of a large population of diploid neoplastic cells with a few higher polyploid cells (Fig 6) (Tables I, IV).

Mosaic ploidy (16 cases) - this pattern showed mosaicism comprising diploid (2c), triploid (3c), tetraploid (4c) populations of proliferative cells (Fig 7). Cancer cells were classified as this pattern if a predominant peak separated from the diploid population exhibited a DNA index between $1 \cdot 1$ and 1.9.

Higher polyploidies (12 cases) - this pattern showed a predominant stemline at the $4 \mathrm{c}$ range (Fig 8). In short, the aneuploid peak separated from the G2/M peak exhibited DNA index $>1.9$.

Twenty eight cases $(58.5 \%)$ showed aneuploidy (mosaic ploidy: 16 cases, higher polyploidies: 12 cases), and in the tubular type of carcinoma aneuploid cases of moderately differentiated carcinoma $(81 \cdot 8 \%)$ were more frequent than those of well differentiated $(20.0 \%)$. Therefore, according to histological grading, the frequency of aneuploidy of cancer with moderate or poor differentiation was significantly higher than that of well differentiated cancer $\left(x^{2}\right.$ test: 0.0192 , Table II). However, the histological typing and frequency of aneuploidy were not significantly correlated (Table III). Benign lesions were all diploid (Table I).

\section{DNA analysis by flow cytometry}

Using flow cytometry, we could distinguish near diploid aneuploidy in eight cases and mosaic ploidies in six of 20 cases of diploidy diagnosed by cytophotometry. On the histogram, near diploid cases had another peak
TABLE II DNA ploidy and histological grading of gastric carcinomas by cytophotometry

\begin{tabular}{llc}
\hline \multirow{3}{*}{ Grading } & \multicolumn{2}{l}{$\begin{array}{l}\text { Cases classified by } \\
\text { cytophotometry }\end{array}$} \\
\cline { 2 - 3 } & Diploid & Aneuploid (\%) \\
\hline Well differentiated cancer & 12 & $4(25)$ \\
Moderate or poor differentiation & 8 & $24(75)^{\star}$ \\
\hline
\end{tabular}

Well differentiated cancer including tub 1 ; cancer with moderate or poor differentiation including tub 2 , por 1 , and por 2 (Table I) ( ${ }^{\star} \chi^{2}$ test: $\left.0 \cdot 0192\right)$.

TABLE III DNA ploidy and histological typing of gastric carcinomas by cytophotometry

\begin{tabular}{lcc}
\hline & \multicolumn{2}{c}{ Cases classified by cytophotometry } \\
\cline { 2 - 3 } Typing & Diploid & Aneuploid (\%) \\
\hline Cancer & & \\
Papillary & 4 & $0(0)$ \\
Tubular & 12 & $22(64 \cdot 7)$ \\
Medullary & 2 & $2(50 \cdot 0)$ \\
Signet & 2 & $4(66 \cdot 7)$ \\
\hline
\end{tabular}

near the G1/G0 (2C) peak and exhibited a DNA index between 1.01 and $1 \cdot 1$ (Fig 9). Besides the three main stemlines of DNA ploidy in carcinoma shown by cytophotometry, a fourth pattern (near diploid aneuploid) was shown by flow cytometry (Table IV). The coefficient of variation of the 78 cases was between $2 \cdot 03-3 \cdot 68$ (mean $=3 \cdot 12)$.

The frequency of aneuploidy measured by flow cytometry $(87.5 \%)$ was higher than that shown by cytophotometry, especially in well differentiated carcinoma (Tables I, V). Furthermore, one of six intestinal metaplasias showed hypo-near diploid aneuploidy (Table I, DNA index $=0.97$ ). With progress of cancer stage and lymph node metastasis, the percentage of aneuploid cases decreased. There were no clear correlations, however, between other clinicopathological variables and DNA patterns (Table V).
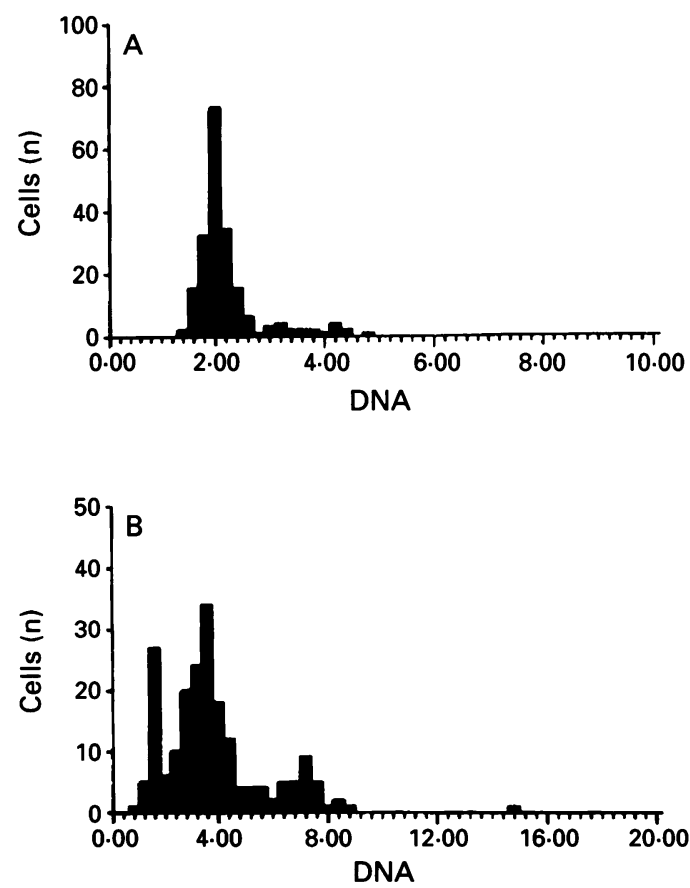

Figure 8: (A) Normal internal standard; (B) aneuploidy showing higher polyploidy by cytophotometry. 
Figure 9: Flow cytometric DNA distribution pattern of near diploidy. ( $A$ ) Normal internal standard; (B) cancer cell nuclei; (C) mixture of normal and cancer cell nuclei at a ratio of 1:3, as determined by flow cytometry. Near diploidy had another peak (arrowhead) near the $2 C$.
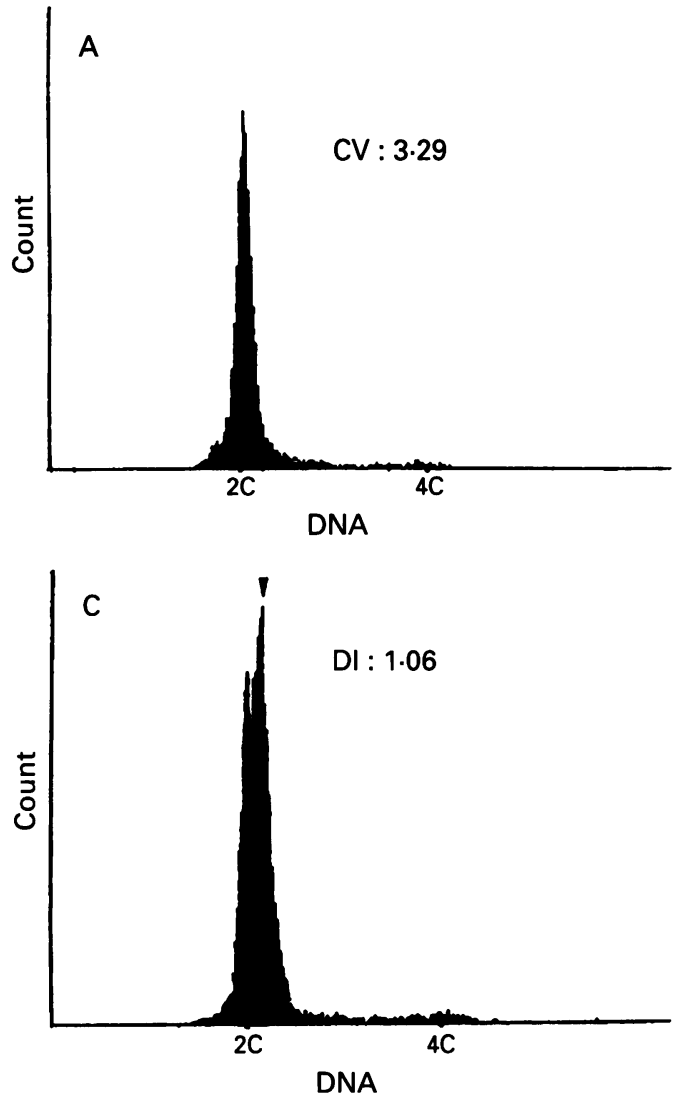

Discussion

Both enzymatic and mechanical methods of obtaining epithelial cells yield mixtures that include interstitial cells. Therefore, there is always doubt as to whether or not the entire epithelium is present in the isolated materials. ${ }^{22-25}$ In case of gene analysis, including DNA measurement, of cancer tissue, contamination by interstitial cells might give rise to serious error. On the other hand, the nonenzymatic gland isolation method used here, which was based on the method by Cheng et $a l^{7-9}$ and modified by Arai, ${ }^{11} 12$ yielded viable glands composed entirely of epithelial cells without contamination by interstitial cells. Most tubular glands of carcinoma could be isolated from the stroma.

The frequency of aneuploid determined by cytophotometry generally reflected the histological grade of the gastric carcinoma. As a rule, aneuploidy was more frequent in the moderately differentiated tubular carcinomas than in well differentiated ones. ${ }^{17}$ Aneuploid cases of gastric carcinomas, were significantly more frequent $(87.5 \%)$ in this study than in others $^{16}$ that used paraffin wax embedded tissue or frozen tissue. And all the carcinomas showed some polyploid cell nuclei on cytophotometry. Thus, existence of a polyploid cell

TABLE IV Ploidy distribution in 48 gastric carcinomas measured by cytophotometry and flow cytometry

\begin{tabular}{lcclll}
\hline & Diploid & $M P$ & $H P$ & $N D$ & Total \\
\hline Cytophotometry & 20 & 16 & 12 & 0 & 48 \\
Flow cytometry & 6 & 22 & 12 & 8 & 48 \\
\hline
\end{tabular}

MP: mosaic ploidy, HP: higher polyploidy, ND: near diploidy.

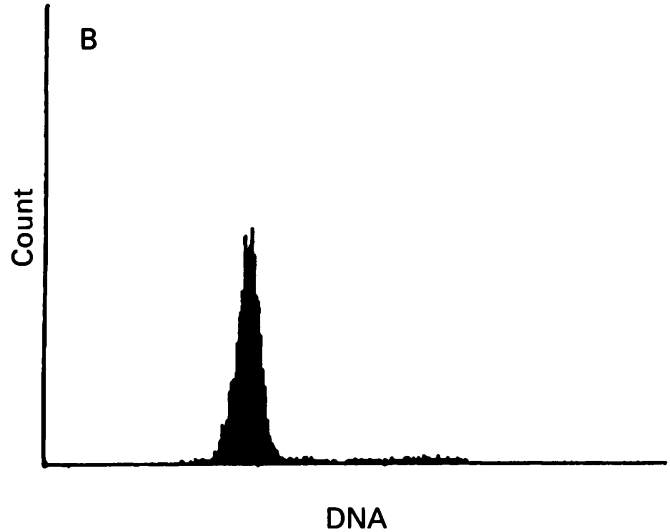

population in the DNA distribution patterns can be regarded as one of the characteristics of gastric carcinoma.

On the other hand, the presence of an aneuploid cell population should be considered an important characteristic of carcinomas, and the degree of proliferative activity generally reflected histological grading. ${ }^{26}$ There were no clear correlations, however, between histological type, clinicopathological variables, and DNA ploidy patterns of the stomach (Tables III, V).

Using flow cytometry we recognised high frequencies of aneuploid patterns in the well differentiated tubular carcinomas. This may point to minor abnormalities of genome at the onset of neoplasia or in low grade adenocarcinoma, which have been overlooked by ordinary flow cytometry.

Adenomas and hyperplastic polyps had no aneuploid stemline, but had more proliferative activity than normal tissue as estimated from the DNA pattern and increased number of $S$ phase cells on cytophotometry (Fig 5). The degree of proliferative activity generally reflected the grade of histological atypia. Only one case of intestinal metaplasia in our study showed hypo-near diploid aneuploidy and decreased S phase cells, while Weiss et al pointed out that in some cases of intestinal metaplasia $S$ phase cells tend to be diminished. They pointed out the same gene abnormality in other benign lesions, such as chronic gastritis and adenomas. ${ }^{20}$

Further investigation using this isolation method might help to analyse precancerous conditions or minimally deviating neoplasms to detect possible near diploid tumours.

TABLE V DNA aneuploidy determined by flow cytometry and clinicopathological variables

\begin{tabular}{|c|c|c|}
\hline Cases & No examined & No positive (\%) \\
\hline \multicolumn{3}{|l|}{ Sex } \\
\hline Male & 30 & $26(86 \cdot 7)$ \\
\hline Female & 18 & $16(88.9)$ \\
\hline \multicolumn{3}{|l|}{ Age } \\
\hline$<60$ & 8 & $8(100)$ \\
\hline$\geqslant 60$ & 40 & $34(85 \cdot 0)$ \\
\hline \multicolumn{3}{|l|}{ Grade } \\
\hline Well differentiated & 16 & $14(87 \cdot 5)$ \\
\hline $\begin{array}{l}\text { Moderate or poor } \\
\text { differentiation }\end{array}$ & 32 & $28(87 \cdot 5)$ \\
\hline \multicolumn{3}{|l|}{ Stage } \\
\hline I & 6 & $6(100)$ \\
\hline II & 18 & $18(100)$ \\
\hline III & 16 & $12(75 \cdot 0)$ \\
\hline IV & 8 & $6(75 \cdot 0)$ \\
\hline \multicolumn{3}{|l|}{ Lymph node metastasis } \\
\hline Positive & 40 & $34(85 \cdot 0)$ \\
\hline Negative & 8 & $8(100)$ \\
\hline
\end{tabular}


1 Kallioniemi OP. Comparison of fresh and paraffin-embedded tissue as starting material for DNA flow cytometry and evaluation of intratumor heterogeneity. Cytometry 1988; 9: 164-9.

2 Merkel DE, McGuire WL. Ploidy proliferative activity and prognosis. DNA flow cytometry of solid tumors. Cancer 1990; 65: 1194-205.

3 Hedley DW, Friedlander ML, Tailor IW, Rugg CA, Musgrove EA. Method for analysis of cellular DNA content of paraffin-embedded pathological material using flow cytometry. F Histochem Cytochem 1983; 31: 1333-5.

4 Barehou G, Gille J, Oevermann E, Lohrs Uso. Flow cytometric analysis of the DNA content in paraffin-embedded tissue from colorectal carcinomas and its prognostic sigtissue from colorectal carcinomas and its prognostic sig-

5 Janne K, Larle W, Trope CG, Farreants GW. Comparison between flow cytometry and image cytometry in ploidy distribution assessments in gynecologic cancer. Cytometry 1992; 13: 314-21.

6 Fausel RE, Brleigh W, Kaminsky DB. DNA quantification in colorectal carcinoma using flow and image analysis cytometry. Anal Quant Cytol Histol 1989; 12: 21-7.

7 Bjerknes M, Chenge $\mathrm{H}$. Method for the isolation of intact epithelium from the mouse intestine. Anat $\operatorname{Rec} 1981$; 199: 565-74.

8 Cheng $\mathrm{H}$, Bjerknes $M$, Amer J. Methods for the determination of epithelial cell kinetic parameters of human colonic epithelium isolated from surgica

9 Cheng $H$, Bjerknes $M$. Whole population cell kinetics and postnatal development of the mouse intestinal epithelium. Anat Rec 1985; 211: 420-6.

10 Roberth W, Anthony B, Prithis B. A method for the isolation and culture of human colonic crypts in collagen gels. In Vitro Cell Dev Biol 1987; 23: 436-42.

11 Nakamura S, Kino I, Baba S. Nuclear DNA content of isolated crypts of background colonic mucosa from patients with familial adenomatous polyposis and sporadic patients with familial adenomatous polyp

12 Arai T, Kino I. Morphometrical and cell kinetic studies of normal human colorectal mucosa. Acta Pathol fpn 1989, 39: 725-30.

13 Japanese Research Society for Gastric Cancer. The general rules for gastric cancer study. 11th ed. Tokyo: Kanahara, 1985: 42-75.
14 Hamada S, Namura K, Itoh R, Fujita S. Characteristics of epithelia and adenoma as revealed by DNA cytofluorometry. Fpn $f$ Cancer Res 1987; 78: 826-32.

15 Hamada S, Itoh R, Fujita S. DNA distribution pattern of the so-called severe dysplasia and small carcinoma the colon and rectum and its possible significance in the tumor progression. Cancer 1988; 61: 1555-62.

16 Morotomi N, Kamachi M, Kagawa K, Kusuzaki K, Deguchi T, Ashihara T. A new method of DNA - cytofluorometry for the paraffin-embedded tissue materials. (In Japanese.) Igakunoayumi 1985; 133: 191-3.

17 Hamada S. Namura K, Itoh R, Fujita S. Characteristics of colorectal epithelia and adenomas as revealed by DNA cytofluorometry. Ipn $f$ Cancer Res (Gann) 1987; 78: cytofluo $826-32$.

18 Hiddeman $W$, Schumann J, Andreeff M, Barlogie B, Herman CJ, Leif RC, et al. Convention on nomenclature for DNA cytometry. Cytometry 1984; 5: 445-6.

19 Macartney JC, Camplejhon RS. DNA flow cytometry of histological material from dysplastic lesions of human gastric mucosa. F Pathol 1986; 150: 113-8.

20 Weib BJ, Gutz HJ, Schroter J, Wildner GP. DNA distribution pattern in chronic gastritis. Scand $\mathcal{f}$ Gastroenterol 1989; 24: 643-8.

21 Lars L, Vindel V, Christensen IJ. A review of techniques and results obtained in one laboratory by an integrated system of methods designed for routine clinical flow cytometric DNA analysis. Cytometry 1990; 11: 753-70.

22 Dupont C, Laburthe M, Broyart JP. Cyclic AMP production in isolated colonic epithelial crypts; a highly sensitive model for the evaluation of vasoactive intestinal peptide action in human intestine. Eur $\mathcal{F}$ Clin Invest 1980; 10: 67-76.

23 Roediger WEW, Truelove SC. Method of preparing isolated colonic epithelial cells (colonocytes) for metabolic studies. Gut 1979; 20: 484-8.

24 Kemler BJ, Alpert E. Inflammatory bowel disease; study of mediated cytotoxicity for isolated human colonic epithelial cells. Gut 1980; 21: 353-9.

25 Freeman HJ, San RHC. Use of unscheduled DNA synthesis in freshly isolated human intestinal mucosal cells for carcinogen detection. Cancer Res 1980; 40: 3155-7.

26 Watanabe H, Jass JR, Sobin LH. Histological typing of oesophageal and gastric tumours. World Health
and Organisation, 1990; 2: 1-2. 